Cite this: Phys.Chem. Chem. Phys. 2020 ...

Received 00th January 20xx, Accepted 00th January 20xx

DOI: $10.1039 / x 0 x \times 00000 x$

\title{
Effects of Crystal Size on Methanol to Hydrocarbon Conversion over Single Crystals of ZSM-5 Studied by Synchrotron Infrared Microspectroscopy ${ }^{+}$
}

\author{
Ivalina B. Minova, ${ }^{a}$ Santhosh K. Matam, ${ }^{\mathrm{b}, \mathrm{c}}$ Alex Greenaway, ${ }^{\mathrm{b}}$ C. Richard A. Catlow, ${ }^{\mathrm{b}, \mathrm{c}, \mathrm{d}}$ Mark D. \\ Frogley, ${ }^{e}$ Gianfelice Cinque, ${ }^{e}$ Paul A. Wright*, ${ }^{a}$ Russell F. Howe. ${ }^{f *}$
}

\begin{abstract}
Operando synchrotron infrared microspectroscopy (OIMS) was used to study the conversion of methanol over coffin-shaped HZSM- 5 crystals of different sizes: large $\left(\sim 250 \times 80 \times 85 \mu \mathrm{m}^{3}\right)$, medium $\left(\sim 160 \times 60 \times 60 \mu \mathrm{m}^{3}\right)$ and small $\left(\sim 55 \times 30 \times 30 \mu \mathrm{m}^{3}\right)$. The induction period, for direct alkene formation by deprotonation of surface methoxy groups, was found to decrease with decreasing crystal size and with increasing reaction temperature. Experiments with a continuous flow of dimethylether showed that evolution of the hydrocarbon pool and indirect alkene formation is also strongly dependent on crystal size. These measurements suggest that the hydrocarbon pool formation and indirect alkene generation should be almost instantaneous at reaction temperatures used in practical catalysis with crystal sizes typically $\sim 1 \mu \mathrm{m}^{3}$.
\end{abstract}

Key words: synchrotron, infrared microspectroscopy, ZSM-5, methanol to hydrocarbons, crystal size

\section{Introduction}

In-situ infrared spectroscopy is a powerful tool in zeolite catalysis, particularly for the observation of adsorbed species under reaction conditions. ${ }^{1}$ Measurements by diffuse reflectance (DRIFTS) give spectra summed over multiple crystals contained in a loose powdered sample, while transmission measurements (TIR) examine a pressed pellet. Neither of these macroscopic sampling techniques can resolve spatial heterogeneities in the sample, and the time resolution of both is restricted by the fact that not all crystals in the sample can respond simultaneously to rapid changes in reactant concentration. Microspectroscopy, on the other hand, focusses the infrared beam onto one individual microcrystal at a time, allowing any spatial inhomogeneity between crystals or within large crystals to be resolved. Oriented groups in the framework or reacting adsorbed species can be determined via linearly polarised infrared radiation on zeolite single crystals. ${ }^{2,3}$ Signalto-noise limitations in conventional laboratory infrared microscopes using a blackbody (Globar) source have prevented

\footnotetext{
a. EastCHEM School of Chemistry, University of St Andrews, St Andrews KY16 9ST; E-mail: paw2@st-andrews.ac.uk; Tel: +44 (0)1334 463793

b. UK Catalysis Hub, Research Complex at Harwell, Rutherford Appleton Laboratory, Oxford, OX11 OFA

Cardiff Catalysis Institute, School of Chemistry, Cardiff University, Cardiff CF10 3AT

d. Department of Chemistry, University College London, , London WC1E 6BT

e. Diamond Light Source, Harwell Science and Innovation Campus, Didcot, OX11 ODE

f. Chemistry Department, University of Aberdeen, AB24 3UE; E-mail:

r.howe@abdn.ac.uk

+ Electronic Supplementary Information (ESI) available: See DOI: $10.1039 / x 0 x x 00000 x$.
}

the rapid scanning needed for studying reactions of adsorbed species in situ.

Infrared radiation from a synchrotron source is up to 100 times brighter than that from a laboratory Globar source, an improvement of a factor of $\sim 20$ in the signal-to-noise ratio. The first applications of synchrotron infrared microspectroscopy to zeolite single crystals were reported by Stavitzky et al. ${ }^{4}$ This and subsequent work has exploited the spatial resolution of the technique down to 3-5 $\mu \mathrm{m} .{ }^{5-7}$ We have recently shown that high temporal resolution can also be achieved with synchrotron infrared microspectroscopy applied to the reaction of methanol in individual crystals of ZSM-5. By coupling the infrared probe with simultaneous mass spectral analysis of evolved reaction products, we could observe the initial steps in the conversion of methanol to hydrocarbons (MTH) within individual crystals on a time scale down to $0.25 \mathrm{s.}^{8}$

The MTH process has been developed and commercialized over ZSM-5 for the production of gasoline due to the concerns about the shortage of oil supply during the oil crisis in the late 1970s, ${ }^{9}$ and more recently dimethylether-to-hydrocarbons over SAPO-34 for production of light olefins with rapid industrial applications demonstrated in China. ${ }^{10}$ The reaction mechanisms have been widely studied since. ${ }^{11}$ There is general agreement that, under steady state working conditions, alkenes and aromatics are produced from a 'hydrocarbon pool' (HCP) within the zeolite pores, comprising a mixture of cyclic alkene and aromatic hydrocarbons from which reaction products are cracked and/or desorbed. It is less well understood how the hydrocarbon pool is formed from methanol, and in particular how the first carbon-carbon bonds are formed. ${ }^{12,13}$ We showed that the surface methoxy groups (SMS) formed by dissociation of methanol at $\mathrm{Br} \varnothing \mathrm{nsted}$ acid sites at $473 \mathrm{~K}$ or above are the key 
intermediates in the subsequent catalysis, ${ }^{8}$ although there is also evidence for some SMS formation at lower temperatures. ${ }^{14,15}$ Deprotonation of the methoxy groups leads to direct alkene formation via "carbene-like" species. The alkenes can desorb or oligomerise, and the oligomer can subsequently crack or cyclise to form the cyclo-alkenyl and aromatic species which constitute the hydrocarbon pool. ${ }^{8}$

Our previous studies investigated the MTH reaction over HZSM- 5 crystals ca. $160 \times 60 \times 60 \mathrm{~mm}^{3}$ in dimensions, prepared via synthesis in an aqueous fluoride solution. To establish the relevance of this SR IR microspectroscopic method to the investigation of reactions over zeolite crystals closer in size to those used commercially (typically $<1 \mu \mathrm{m}^{3}$ ), a comparison was made here between HZSM- 5 crystals of a range of sizes, down to ca. $30 \mu \mathrm{m}$ in their 'middle' dimension, which approaches the limit that can be studied with the available experimental set-up (above the optical diffraction limit size of the infrared focal spot, and with overall sample thickness that guarantees an absorbance spectrum has a sufficient signal-to-noise ratio during a time resolved study). This was made possible by the development of a synthetic method that allowed the crystal size to be varied without significantly changing the framework composition (the Si/Al ratio), and thereby enabled the relative importance of reaction and diffusion processes to be varied. Furthermore, whereas the ability to prepare ZSM- 5 crystals with dimensions of $c a .100 \mu \mathrm{m}$ is relatively rare among high silica zeolites, $<30 \mu \mathrm{m}$ is a more accessible synthetic target.

\section{Experimental}

2.1 Synthesis of large, medium and small HZSM-5 crystals. Twinned crystals of ZSM-5 were prepared with large (ca. $250 \times 80 \times 85 \mu^{3}$ ), medium (ca. $160 \times 60 \times 60 \mu m^{3}$ ) and small crystal size (ca. $55 \times 30 \times 30 \mu \mathrm{m}^{3}$ ) by a modification of the ammonium fluoride route reported by Guth et al. ${ }^{16}$ and Losch et al. ${ }^{17}$ In a typical procedure, tetrapropylammonium bromide (TPA, $0.27 \mathrm{~g}, 1.0 \mathrm{mmol}), \mathrm{NH}_{4} \mathrm{~F}(0.28 \mathrm{~g}, 7.4 \mathrm{mmol})$, $\mathrm{Al}\left(\mathrm{NO}_{3}\right)_{3} .9 \mathrm{H}_{2} \mathrm{O}(0.19 \mathrm{~g}, 0.7 \mathrm{mmol})$ were added to deionised water $(9.00 \mathrm{~g}, 500 \mathrm{mmol})$ and fumed silica $(0.60 \mathrm{~g}, 10 \mathrm{mmol})$ was slowly added. The gel composition $\left(100 \mathrm{SiO}_{2}\right.$ : $\left.5 \mathrm{Al}\left(\mathrm{NO}_{3}\right)_{3} .9 \mathrm{H}_{2} \mathrm{O}: \quad 75 \mathrm{NH}_{4} \mathrm{~F}: \quad 5000 \mathrm{H}_{2} \mathrm{O}: \quad 9.1 \mathrm{TPABr}\right)$ corresponded to Si:Al 20:1. The gel was stirred at room temperature for $2 \mathrm{~h}$ before being sealed in a Teflon lined autoclave ( $30 \mathrm{~mL}$, Parr) and heated at $463 \mathrm{~K}$ for 10 days under static conditions, yielding the medium crystal size.

A smaller crystal size was obtained by increasing the amount of $\mathrm{Al}\left(\mathrm{NO}_{3}\right)_{3}$ in the synthesis gel (Si:Al 12:1), resulting in crystals of similar shape but significantly reduced volume, creating shorter diffusion pathlengths. Despite variations in the Si:Al ratio in the synthesis gels (Table 1 ), it was found that the crystals do not incorporate more than four Al atoms per unit cell, and any excess aluminium precipitates out as larger clumps of material which can be removed by sieving. Finally, large crystals (ca. $35 \times$ larger in volume compared to the small) were obtained from a synthesis gel with Si:Al 20:1, at prolonged synthesis time ( 28 days at $463 \mathrm{~K}$ ). The crystals were recovered by vacuum filtration, washed with deionised water and dried overnight at $373 \mathrm{~K}$. Prior to spectroscopic studies, crystals were calcined by heating at $823 \mathrm{~K}$ (reached at $2 \mathrm{~K} \mathrm{~min}^{-1}$ ) in oxygen for $64 \mathrm{~h}$.

\begin{tabular}{cccccc}
\hline \multicolumn{6}{l}{ Table 1 Synthesis gel molar ratios for large, medium and small crystals } \\
\hline $\begin{array}{c}\text { Gel comp./ } \\
\text { Sample ID }\end{array}$ & $\mathrm{SiO}_{2}:$ & $\mathrm{Al}^{3+}:$ & $\mathrm{F}-:$ & $\mathrm{H}_{2} \mathrm{O}:$ & TPA $^{+}$ \\
\hline Large & 100 & 5 & 45 & 2526 & 9.1 \\
Medium & 100 & 5 & 75 & 5000 & 9.1 \\
Small & 100 & 8.5 & 75 & 5000 & 9.1 \\
\hline
\end{tabular}

2.2 Sample characterisation methods. Samples were characterised by thermogravimetric analysis, $\mathrm{CHN}$ analysis, X-ray powder diffraction (Stoe with $\mathrm{Cu} \mathrm{K}_{\alpha}$ radiation), scanning electron microscopy (JEOL JSM-5600 SME with Oxford INCA Energy 200 electron dispersive $\mathrm{X}$-ray analysis) and Ar ion milling was used to cleave the crystal and study the elemental composition from the entire cross section of the crystal (Hitachi S-5500). Solid-state MAS NMR spectra were acquired on a Bruker Advance III $400 \mathrm{MHz}$ spectrometer equipped with a $9.4 \mathrm{~T}$ widebore superconducting magnet. Prior to obtaining quantitative ${ }^{27} \mathrm{Al}$ MAS NMR, the sample was left to hydrate overnight in a moist atmosphere. The Brønsted acid sites were titrated with ammonia and quantified on a Micrometrics AutoChem 2920 coupled to a Pfeiffer Vacuum ThermoStar ${ }^{\mathrm{TM}}$ quadrupole mass spectrometer. $\mathrm{N}_{2}$ adsorption isotherms were measured volumetrically (Micrometrics Tristar) after dehydrating the sample under vacuum at $473 \mathrm{~K}$ overnight. Catalytic tests were performed on a Salamander fixed-bed microreactor. The calcined crystals were diluted with quartz and tested for the dimethyl-ether-tohydrocarbons reaction at weight hourly space velocity (WHSV) of $3.8 \mathrm{~h}^{-1}$. Gas phase products were separated and analysed by on-line gas chromatograph (Agilent GC) equipped with a capillary GC GasPro column $(0.32 \mathrm{~mm} \times 30 \mathrm{~m})$ using a Flame Ionisation Detector (FID).

2.3 Operando Infrared Microspectroscopy (OIMS) experiment. $\mathrm{HZSM}-5$ crystals were sprinkled on $\mathrm{CaF}_{2}$ windows and placed on the heated sample stage of an environmental Linkam FTIR600 cell (c.a. $50 \mathrm{~mL}$ internal volume) mounted on a (Bruker) Hyperion 3000 IR microscope coupled to a Vertex 80V FTIR at MIRIAM beamline B22 of Diamond Light Source. The infrared experiment requires only single crystals of the catalyst. To improve the sensitivity of the MS detection we typically added around $1 \mathrm{mg}$ (up to $3 \mathrm{mg}$ ) of zeolite to the cell and checked that the spectra seen from one crystal were reproducibly seen from other crystals in the sample. The infrared experiments were collected in transmission from individual crystals at spatial resolution down to $10 \times 10$ micron at the sample using a $36 \times$ objective/condenser optics, averaging 16 scans at $4 \mathrm{~cm}^{-1}$ resolution, i.e. typically collecting an $I R$ spectrum every two seconds. The output of the gas phase products from the cell was analysed by mass spectrometry (Pfeiffer or EcoSys) and correlated with the time-resolved IR spectral changes. Gases or liquids were introduced into a nitrogen flow $\left(100 \mathrm{~mL} \mathrm{~min}^{-1}\right)$ upstream of the heated cell at temperatures up to $673 \mathrm{~K}$ and ambient pressure. Multiple methanol pulses (each pulse $8 \mu \mathrm{L}$ in volume) were syringe injected, and dimethylether $\left(5 \mathrm{~mL} \mathrm{~min}{ }^{-1}\right)$ was diluted in the nitrogen stream and introduced in a continuous flow. 


\section{Results}

3.1 Structure, calcination and unit cell composition.

Upon removal of the structure directing agent used in the synthesis (Fig. S1 TGA and Table S1 CHN analysis, ESI+), the protonic form of ZSM-5 (here HZSM-5) is obtained with a high surface area $\left(\sim 350 \mathrm{~m}^{2} \mathrm{~g}^{-1}\right)$ as confirmed by nitrogen adsorption (Fig. S2 for XRD and Fig. S3 for $\mathrm{N}_{2}$ adsorption, ESI+). SEM micrographs of the three crystals display a highly uniform crystal size distribution for each crystal batch (Fig. 1). This is important as a separate sample of freshly-calcined HZSM-5 crystals was used for each IR experiment.
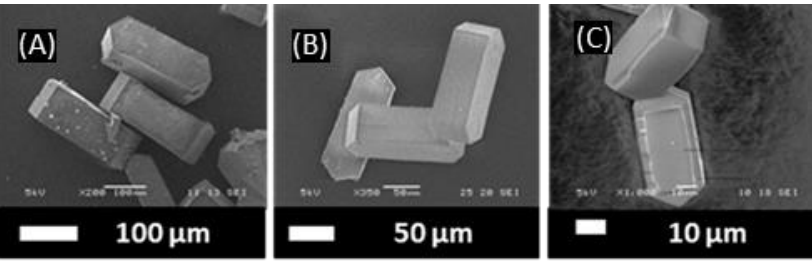

Fig. 1 SEM images of (A) large, (B) medium and (C) small HZSM-5 crystals.

The ${ }^{27} \mathrm{Al}$ and ${ }^{29} \mathrm{Si}$ NMR spectra of the crystals are shown in Fig. 2. The ${ }^{27} \mathrm{Al}$ peak at $53-56 \mathrm{ppm}$ confirms $\mathrm{Al}$ is tetrahedrally coordinated into the lattice in all three sets of crystals. ${ }^{18,19}$ The ${ }^{29} \mathrm{Si}$ spectra of all three show the profile expected for crystalline HZSM-5 with Si: Al of 25.20 The as-prepared crystals display a classic hour-glass outline in optical micrographs (see inset in Fig. 2). This is due to intergrowths of two different orientations of the $a$ and $b$ axes of the crystal. ${ }^{21}$

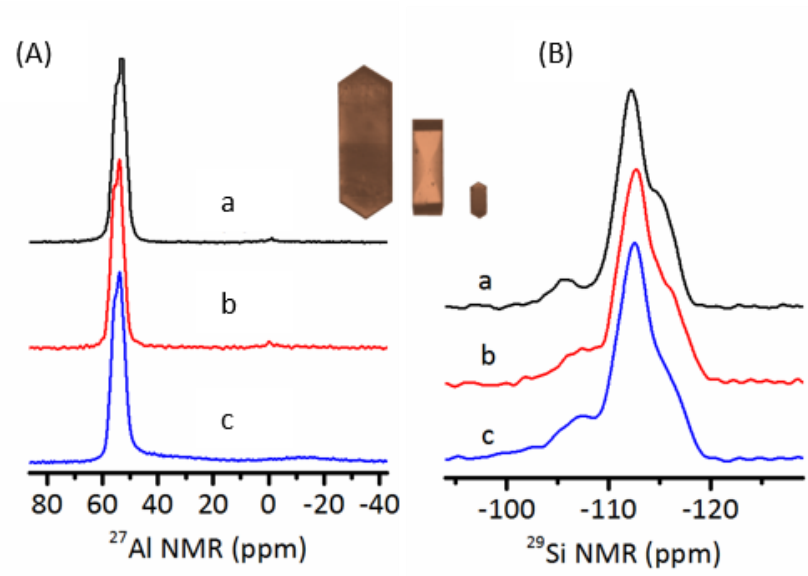

Fig. $2{ }^{27} \mathrm{AI}$ MAS NMR (A) and ${ }^{29} \mathrm{Si}$ MAS NMR (B) of the (a) large, (b) medium and (c) small HZSM-5 crystals. Inset. Optical images of the three crystals as seen under polarised light.

Elemental analysis of the crystals by bulk EDX and crosssectional EDX on cleaved crystals gave $\mathrm{Si}$ : Al ratios between 25 and 36 (Table 2). Brønsted acid site concentrations determined from ammonia TPD measurements (Table S2, ESI ${ }^{\dagger}$ ) gave similar Si: Al ratios, and Al line cross-sectional profiles revealed that the aluminium is homogeneously distributed across the cleaved crystals (Fig. S4, ESI ${ }^{+}$), consistent with the reported uniformity of composition achieved with the use of fluoride in the synthesis. ${ }^{17}$

\begin{tabular}{cccc}
\hline Table 2 Characterisation of Si: Al ratio from different techniques \\
\hline $\begin{array}{c}\mathrm{a} \times \mathrm{b} \times \mathrm{c} \\
\left(\mu \mathrm{m}^{3}\right)\end{array}$ & $\begin{array}{c}250 \times 80 \times 85 \\
\text { Large }\end{array}$ & $\begin{array}{c}160 \times 60 \times 60 \\
\text { Medium }\end{array}$ & $\begin{array}{c}55 \times 30 \times 30 \\
\text { Small }\end{array}$ \\
\hline EDS & 34 & 31 & 30 \\
$\mathrm{CS}-\mathrm{EDS}$ & 36 & 24 & 24 \\
$\mathrm{NH}_{3}$-TPD & 24 & 21 & 21
\end{tabular}

3.2 Microcatalytic test. The performance of the crystals in a conventional microcatalytic test was confirmed by carrying out DME conversion at $673 \mathrm{~K}$. Table 3 shows conversion and product selectivity data after 5 minutes on stream (conversions decreased at longer reaction times due to deactivation). Olefins are the major products under these conditions, but significant amounts of aromatics are also formed.

Table 3 Microreactor selectivity and conversion data from dimethylether (DME) conversion over the three different crystal sizes of HZSM-5 at 5 min time-on-stream, $673 \mathrm{~K}, \mathrm{WHSV}=3.8 \mathrm{~h}^{-1}$

Microreactor selectivity Large Medium Small

\begin{tabular}{cccc}
\hline ethene & 23.1 & 24.5 & 32.2 \\
propene & 42.9 & 46.0 & 42.9 \\
C4 $^{\mathrm{a}}$ & 20.3 & 19.5 & 18.0 \\
$\mathrm{C}^{\mathrm{a}}$ & 5.6 & 4.9 & 4.7 \\
$\mathrm{C}^{+}$ & 6.3 & 5.1 & 2.15 \\
$\mathrm{C}_{2} / \mathrm{C}_{3}{ }^{\mathrm{b}}$ & 0.5 & 0.5 & 0.8 \\
\hline DME Conversion & $99 \%$ & $95 \%$ & $100 \%$ \\
\hline
\end{tabular}

IR spectra of individual dehydrated HZSM-5 crystals. IR spectra were recorded for the large HZSM-5 (ca. $250 \times 80 \times 85{\mu \mathrm{m}^{3}}^{3}$ ), medium $\left(c a .160 \times 60 \times 60 \mu \mathrm{m}^{3}\right)$ and small crystal sizes $(c a .55 \times$ $30 \times 30 \mu \mathrm{m}^{3}$ ) after dehydration at $623 \mathrm{~K}$ in flowing nitrogen. Fig. 3 compares spectra of the three dehydrated crystals. Each crystal shows two hydroxyl bands in the high wavenumber region, the sharp band at $3600 \mathrm{~cm}^{-1}$ is due to the $B r \varnothing n s t e d$ acid site (BAS) and the small band at $3735 \mathrm{~cm}^{-1}$ is due to terminal silanol functional groups located at the interfaces between the crystal intergrowths or other defects. Closely similar spectra were measured from different crystals within each batch, and from different regions of individual crystals. In particular, we could not distinguish any differences in the relative populations of silanol and BAS hydroxyl groups between the different areas of the intergrown crystals. (Fig. S4 for FTIR spectra of different crystals, ESI + ). The lower wavenumber bands at 1995, 1870 and $1630 \mathrm{~cm}^{-1}$ are due to overtones and combination bands of Si-O-Al stretching and bending modes of the zeolite framework. The intensities of these bands are determined by the thickness of the zeolite crystals; the spectra in Fig. 3 have been normalised against the intensity of the $1870 \mathrm{~cm}^{-1}$ band, and a rubber-band base-line correction applied. Typically, spectra of the dehydrated zeolites are subtracted from those measured during reaction, and the difference spectra presented. 


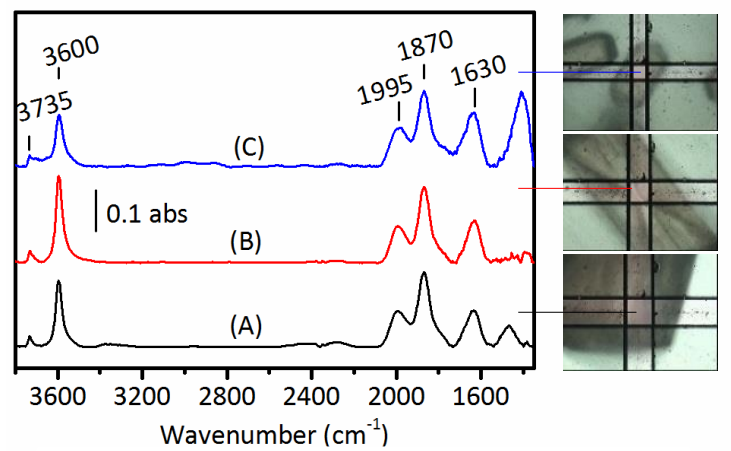

Fig. 3 SR-IR spectra of dehydrated individual HZSM-5 crystals (A) large, (B) medium and (C) small. Spectra are scaled based on the framework band at $1870 \mathrm{~cm}^{-1}$ for comparison of the intensity of the Brønsted acid site (scaling factors: circa $\times 3, \times 2$ and 1 for the large, medium and small crystal sizes, respectively).

3.3 Methanol pulses. Fig. 4 provides an overview of the species that are detected by infrared microspectroscopy in the early stages of the MTH reaction over HZSM-5, namely adsorbed methanol, at $523 \mathrm{~K}$ and hydrogen bonded DME at $573 \mathrm{~K}$ over a large crystal, and methoxy groups and alkene oligomers at $573 \mathrm{~K}$ over a medium crystal. (A full sequence of spectra at 2 second intervals following injection of a methanol pulse at $523 \mathrm{~K}$ on a medium crystal is given in Fig S6, ESIt). When methanol is first injected into the zeolite it is hydrogen bonded to the BAS. At $523 \mathrm{~K}$, the hydrogen bonded methanol is quickly converted to hydrogen bonded dimethylether, which slowly desorbs from the zeolite, recovering part of the original BAS hydroxyls intensity and leaving a weak residual spectrum of surface methoxy groups (SMS). After a further delay, the BAS hydroxyl band intensity dramatically increases, and the SMS spectrum is converted to that of alkene oligomer, identical to that formed when propene is injected into the zeolite at the same temperature $(523 \mathrm{~K}) .^{8}$

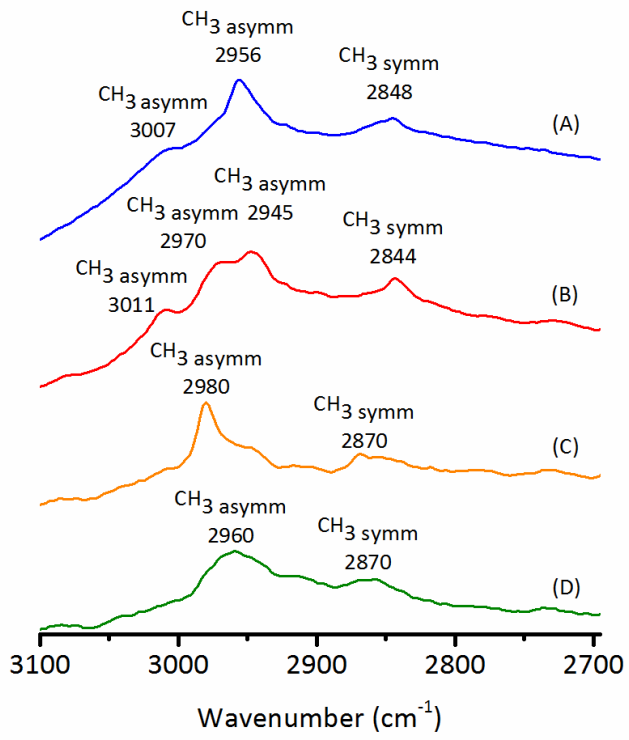

Fig. 4 Difference FTIR spectra of a medium size HZSM-5 crystal, showing the sequence observed following introduction of methanol at $523 \mathrm{~K}$. The marke methanol at $523 \mathrm{~K}$ (B) hydrogen bonded dimethylether at $573 \mathrm{~K}$, (C) surface methoxy groups at $573 \mathrm{~K}$ and (D) alkene oligomers at $573 \mathrm{~K}$.
Having described the type of adsorbed species formed in the early stages of the MTH reaction over HZSM-5, next, the response of three different sizes of crystal to a pulse of methanol at $573 \mathrm{~K}$ is compared (Fig. 5). The top panels show the MS analyses of the effluent gases, the central panels show the intensity of the BAS hydroxyl band $\sim 3600 \mathrm{~cm}^{-1}$ as a function of time (expressed as a percentage of the original intensity in the dehydrated crystal) and the bottom panels show IR spectra in the $\mathrm{CH}$ stretching region at the reaction times indicated. In all crystal sizes studied here, oligomeric hydrocarbon species are observed immediately after the loss of methoxy groups at the end of the induction period.
(A)
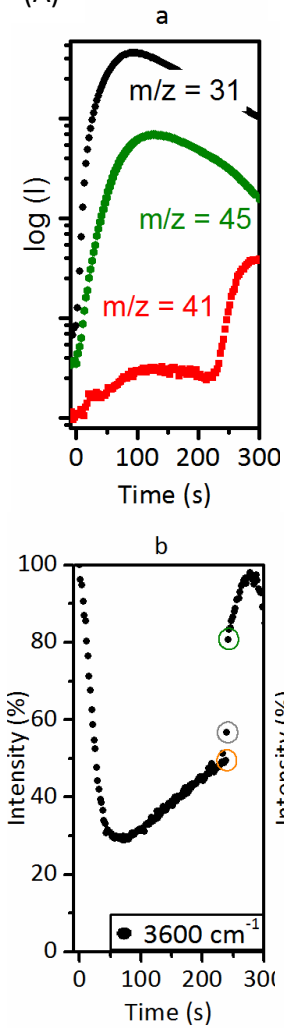

C

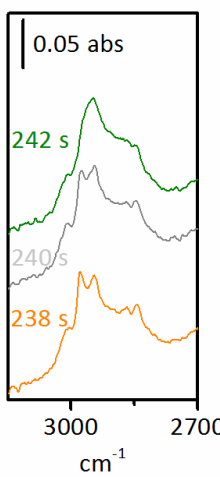

(B)

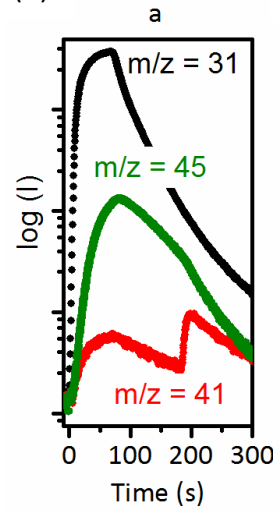

(C)
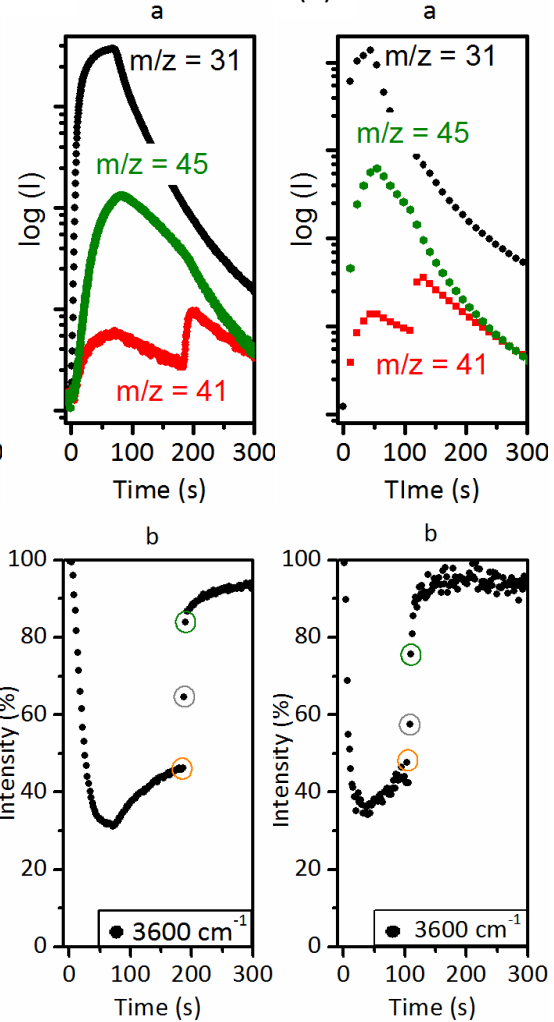

C

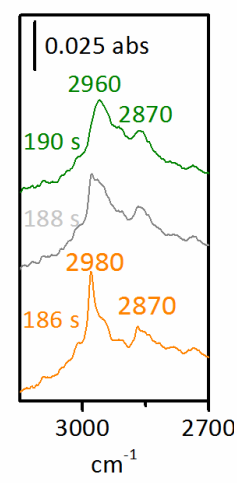

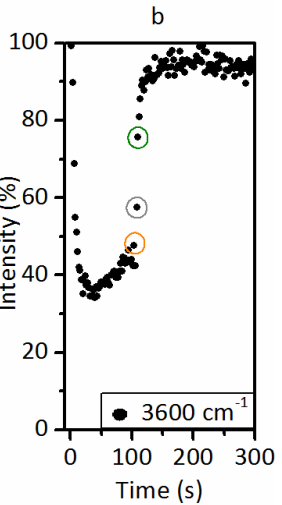

C

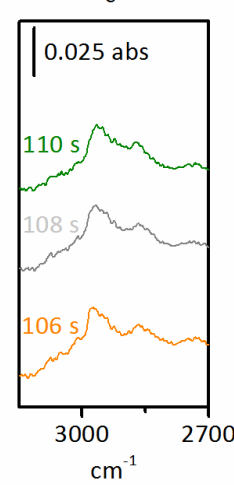

Fig. 5 Comparison of (A) large, (B) medium and (C) small crystals during one $8 \mu \mathrm{L}$ methanol pulse injected into a $\mathrm{N}_{2}$ flow of $100 \mathrm{~mL} \mathrm{~min}^{-1}$ at $573 \mathrm{~K}$. (a) Mass spectra traces recorded during these experiments, $\mathrm{m} / \mathrm{z}=31$ measures methanol, $\mathrm{m} / \mathrm{z}=45$ DME, $\mathrm{m} / 2$ ing 1 pre course of the z conte hydroxyl $v(\mathrm{OH}) 360 \mathrm{~cm}^{-1}$ band intensity relative to an activated crystal recorded at 2 s intervals. (c) Evolution of the $\mathrm{CH}$ stretching bands during the rapid regeneration of the zeolite hydroxyls during the experiments in (A, B and $C)$, respectively. 
In the large crystal (Fig. $5 \mathrm{~A}$ ), the loss of $\mathrm{OH}$ intensity following injection of methanol is followed by a slow recovery as hydrogen bonded DME is desorbed, then after an induction period of $\sim 240 \mathrm{~s}$ there is a remarkably rapid recovery of $\mathrm{OH}$ intensity. The mass spectral traces during this experiment show a clear delay in evolution of DME after the methanol injection, but the first appearance of propene occurs at the same point as the recovery of $\mathrm{OH}$ intensity. The infrared spectrum in the $\mathrm{v}(\mathrm{CH})$ region shows the presence of SMS and some residual hydrogen bonded DME (orange trace in Fig. 5A(c)). At $242 \mathrm{~s}$ all of the SMS and DME have gone and the spectrum is that of the oligomer formed from alkenes (green trace in Fig. 5A(c) and Fig. 4).

In the large crystal, the loss of SMS and residual DME occurs at the same time as the BAS hydroxyl groups are recovered and propene is evolved. This could be taken as evidence of a reaction between SMS and residual DME regenerating BAS described by eqn. (1):

$$
\mathrm{ZOCH}_{3}+\mathrm{CH}_{3} \mathrm{OCH}_{3} \rightarrow \mathrm{ZOH}+\mathrm{CH}_{3} \mathrm{CH}_{2} \mathrm{OCH}_{3}
$$

eqn. 1

However, the corresponding data for medium and small crystals do not support this explanation (Fig. $5 \mathrm{~B}-\mathrm{C}$ ). In the medium crystals, the spectrum remaining at the point where the BAS OH band intensity begins to recover (orange trace in Fig. $B(C)$ shows only SMS with little remaining DME adsorbed on the crystal is seen by IR), and this is equally clear for the small crystals.

The effect of crystal size on the induction time for propene formation, BAS hydroxyl recovery and SMS conversion to oligomer is dramatic. We attribute these differences to the different length of diffusion pathways in the different sized crystals. From these experiments the deprotonation of SMS, which initiates propene formation, appears to occur only after desorption of most or all of the initially hydrogen bonded DME, which occurs more rapidly from the medium and small crystals than from the large crystals.

Previous evidence for direct formation of hydrocarbons from SMS in ZSM-5 has come from NMR experiments of Wang et al. ${ }^{22}$, who suggest that carbene or ylide intermediates may be involved. We note also that infrared evidence for a carbene-like reactivity of SMS in ZSM-5 towards light alkenes (e.g. methylation of ethene to form propene) has been presented by Yang et al. ${ }^{23}$

The direct formation of alkenes through a carbene-like intermediate requires mobility of SMS within the zeolite such as described by eqn. (2) and (3) below:

$$
\begin{array}{ll}
2 \mathrm{CH}_{3} \mathrm{OZ} \rightarrow \mathrm{HOZ}+\mathrm{CH}_{3} \mathrm{CH}_{2} \mathrm{OZ} \rightarrow \mathrm{C}_{2} \mathrm{H}_{4}+2 \mathrm{HOZ} & \text { eqn. } 2 \\
\mathrm{HOZ}+\mathrm{C}_{2} \mathrm{H}_{4}+\mathrm{CH}_{3} \mathrm{OZ} \rightarrow \mathrm{HOZ}+\mathrm{C}_{3} \mathrm{H}_{6} & \text { eqn. } 3
\end{array}
$$

The alkenes formed can desorb from the zeolite or oligomerise at BAS in the zeolite (giving the observed $\mathrm{v}(\mathrm{CH})$ bands identical to those formed on injecting propene or ethene into the zeolite). ${ }^{8}$ We emphasize that this chemistry is occurring only during the initial interaction of methanol with a dehydrated zeolite crystal.
Comparison of the reactivity of methanol injected into a large and small crystal at $573 \mathrm{~K}$ is made in Fig. 6 . In both crystals, a clear induction period for propene formation is seen only in the first methanol pulse. More propene is produced in the second, third and fourth pulses, while the DME yield reduces, see MS plots in (a). The higher propene and ethene yields seen in second and subsequent pulses in Fig. 6(a) suggest that alkene formation through this indirect process is more productive than that occurring during the initial deprotonation of SMS. There is also some indication of ethene formation from the second pulse onwards (the high baseline at $\mathrm{m} / \mathrm{z}=27$ is due to overlap with the $\mathrm{m} / \mathrm{z}=28$ peak of the nitrogen carrier gas). Methyl aromatic products are also seen to be rising with successive methanol pulses (the $\mathrm{m} / \mathrm{z}=91$ peak is due to the tropylium cation, which is an abundant ion rearrangement product in the mass spectra of methyl aromatic compounds).

The behaviour of the BAS OH band at $3600 \mathrm{~cm}^{-1}$ is also different in the second and subsequent methanol pulses from that seen in the first pulse, plots in Fig. 6(b). The recovery of BAS after each methanol pulse gradually diminishes and the number of residual BAS remaining in the zeolite declines, especially in the large crystal.

Two new bands appear and grow in the $1650-1450 \mathrm{~cm}^{-1}$ region, during the four successive methanol pulses at $573 \mathrm{~K}$, plots in Fig. 6(c). The time dependence of the $1510 \mathrm{~cm}^{-1}$ and $1620 \mathrm{~cm}^{-1}$ bands is clearly different. In both crystal sizes, the $1510 \mathrm{~cm}^{-1}$ band appears first, and decays less rapidly than the $1620 \mathrm{~cm}^{-1}$ band. However, in the smaller crystal, the growth of the $1510 \mathrm{~cm}^{-1}$ band occurs notably faster in the first pulse. Nonetheless, the build-up of these species correlates with the declining concentration of BAS remaining after each methanol pulse, supporting the assignment that they are associated with the hydrocarbon pool (HCP) accumulating in the zeolite.

The band at $1510 \mathrm{~cm}^{-1}$ (with a shoulder at $1460 \mathrm{~cm}^{-1}$ and accompanying $\mathrm{v}(\mathrm{CH})$ bands at $3120 \mathrm{~cm}^{-1}$ and $2910 \mathrm{~cm}^{-1}$ was assigned to the 1,3-dimethylcyclopentenyl cations (Scheme 1 ). ${ }^{8}$

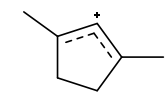

Scheme 1. Structure of 1,3-dimethylcyclopentenyl cations (DMCP).

DMCP has been identified by NMR as the first cyclic component of the hydrocarbon pool to be formed in HZSM-5 during the $\mathrm{MTH}$ reaction, ${ }^{24}$ and the vibrational frequencies observed by IR microcrystal spectroscopy are close to those of the gas phase cations reported elsewhere. ${ }^{25}$ Once DMCP forms in HZSM-5 during the MTH reaction, it may undergo methylation and skeletal rearrangement to form toluene or other methylated aromatic products. DMCP may also crack to form alkenes. ${ }^{24}$ The $1620 \mathrm{~cm}^{-1}$ band was assigned to a $\mathrm{C}=\mathrm{C}$ stretching mode of adsorbed methyl aromatic species. ${ }^{8}$

At the low temperatures investigated so far $(<623 \mathrm{~K})$, hydrogen bonded species were seen during the leading edge of the methanol pulse. 
(A)
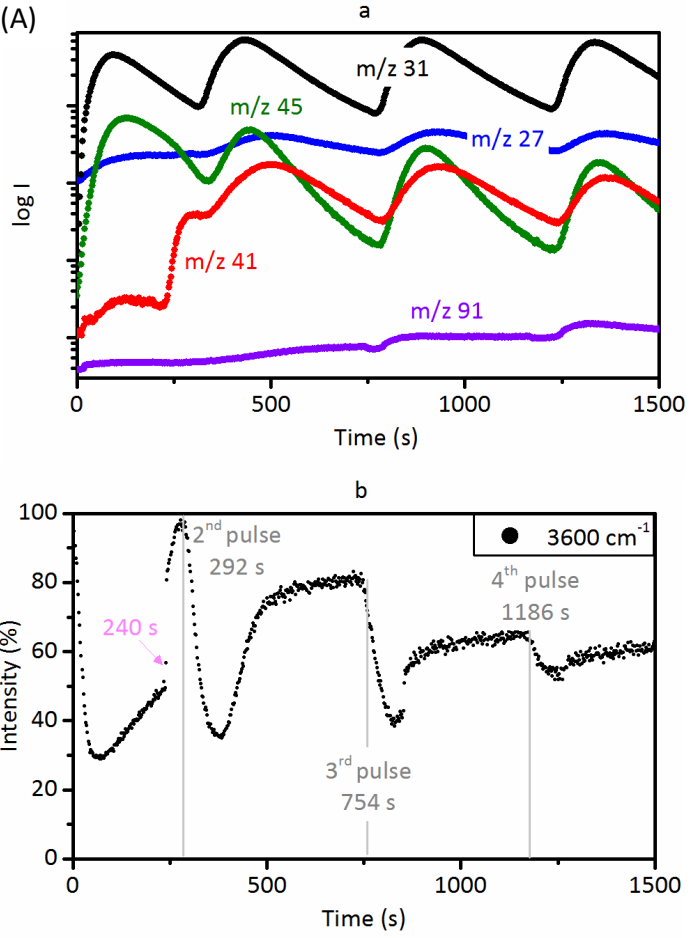

(B)

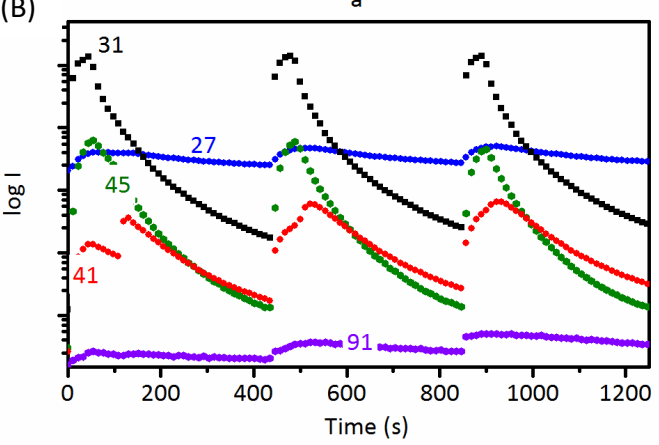

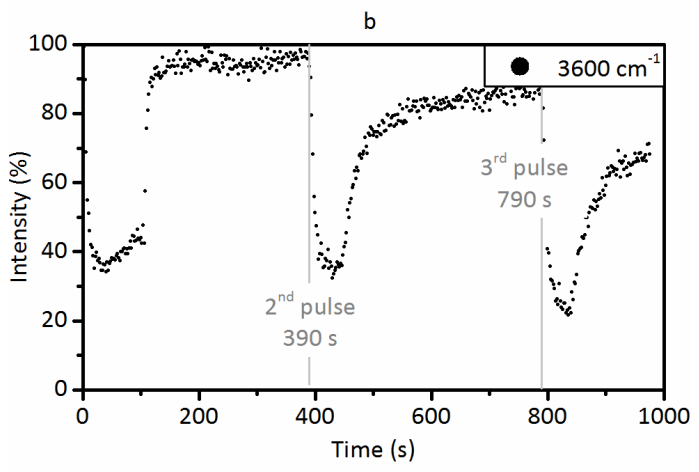
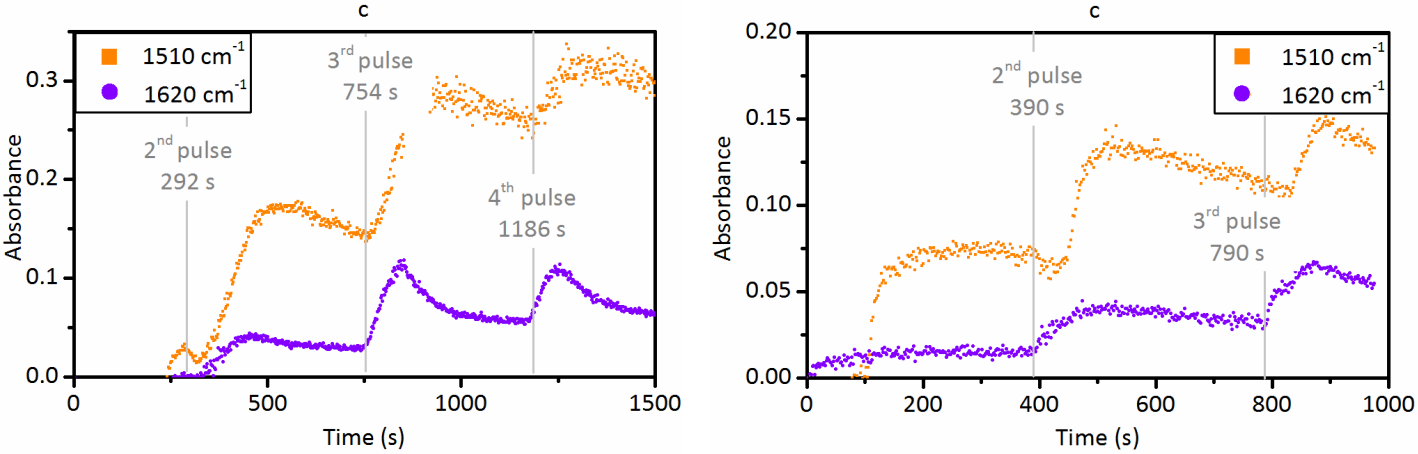

Fig 6 Comparison of a (A) large and (B) small crystal during 4 and 3 successive $8 \mu \mathrm{L}$ methanol pulses at $573 \mathrm{~K}$, respectively. (a) Gas phase products detected by onlineMS during injection of methanol. (b) Time dependence of the infrared $\mathrm{OH}$ stretching band at $3600 \mathrm{~cm}^{-1}$ recorded at $2 \mathrm{~s}$. (c) Extracted intensity of the bands at $1510 \mathrm{~cm}-1$ (orange) and $1620 \mathrm{~cm}^{-1}$ (purple) recorded at $2 \mathrm{~s}$ intervals during the experiments in (A) and (B), respectively.

Considering the formation of aromatics is promoted at higher temperatures, it was desirable to compare the different crystals at higher reaction temperatures, where no hydrogen bonding is seen and the differences between the production of aromatics becomes more apparent. It was found that at higher reaction temperatures $(623 \mathrm{~K})$ and in smaller crystals the $1620 \mathrm{~cm}^{-1}$ band is more intense, and the relative yields of aromatic products at $\mathrm{m} / \mathrm{z}=91$ detected in the MS are higher (Fig. 7). The induction period for recovery of BAS, loss of SMS and evolution of propene during the first methanol pulse at this temperature is less than $10 \mathrm{~s}$. The relative yields of alkene products remain similar between the medium and small crystals, as are the $1510 \mathrm{~cm}^{-1}$ band intensities. However, the $1620 \mathrm{~cm}^{-1}$ band has two orders of magnitude (integrated area) higher relative intensities compared to the large and medium crystals, and an enhanced yield of methylaromatic products is detected in the MS for the small crystal. At this temperature both the 1510 and $1620 \mathrm{~cm}^{-1}$ bands are diminished equally rapidly, and the loss of these bands appears to correlate with recovery of the BAS during the second and third pulses.

At low temperatures ( $<523 \mathrm{~K}$ ) methanol is converted slowly to DME, which involves the formation of SMS, but the deprotonation of the SMS occurs only after hydrogen bonded DME is desorbed. At higher temperatures hydrogen bonded DME is quickly desorbed, the formation of alkenes and oligomer follows, and in subsequent pulses of methanol the cyclic HCP species are seen.

The important conclusion regarding the significance of crystal size is that the induction time for deprotonation of SMS, regeneration of BAS and formation of alkenes decreases as the crystal size is reduced. We attribute this to the faster desorption of hydrogen bonded DME out of the smaller crystals i.e. the presence of excess DME in the crystals appears to block the SMS deprotonation chemistry. 
(A)

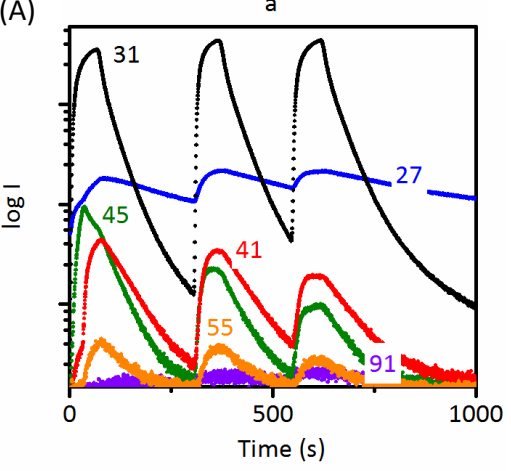

(B)

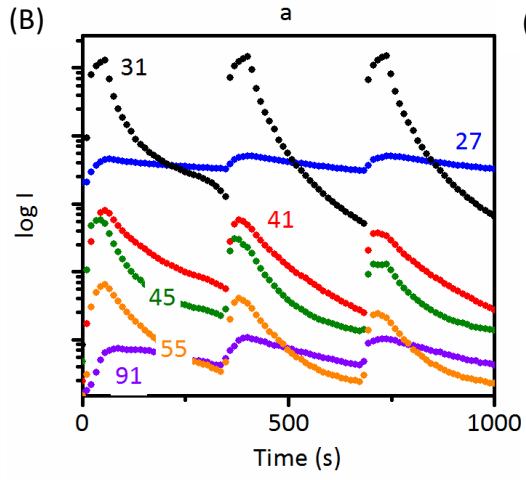

b
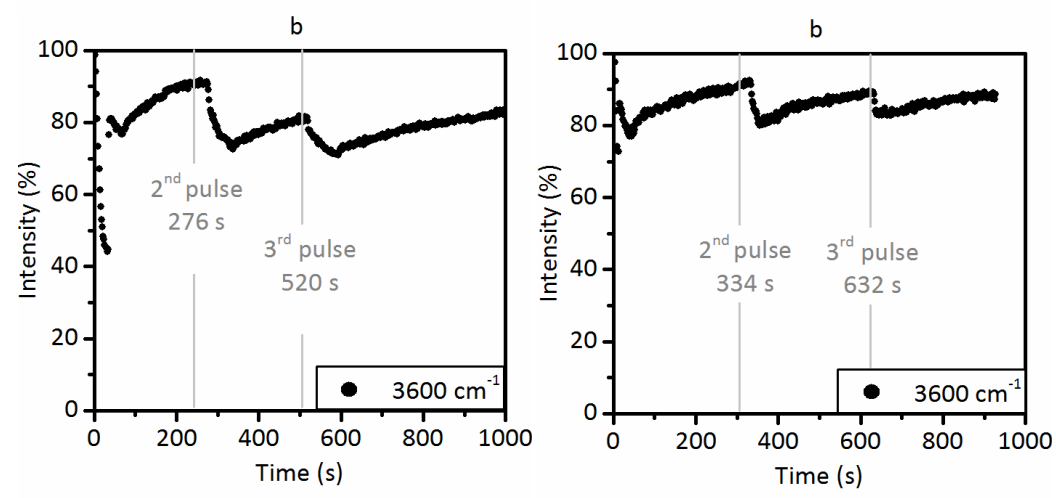

(C)
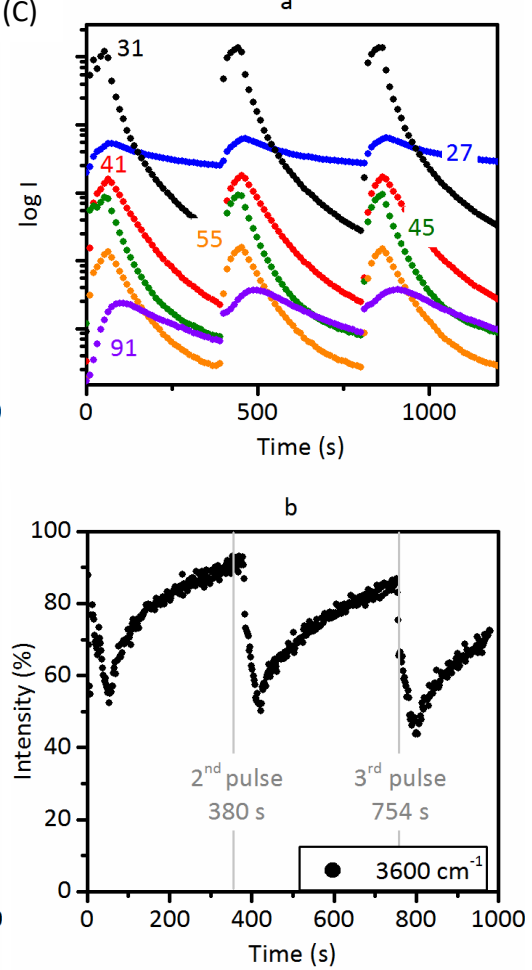
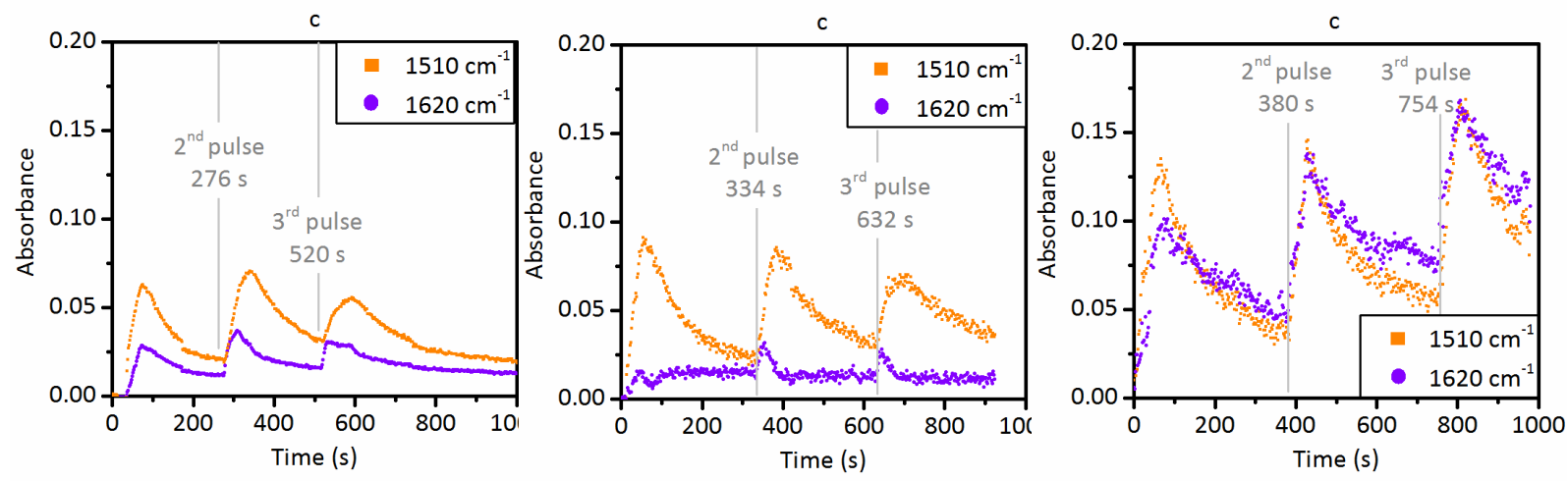
Fig. 7 Comparison of (A) large (B) medium and (C) small crystal of HZSM-5 crystal during the injection of 3 successive $8 \mu$ Lpulses of methanol at $623 \mathrm{~K}$. (a) On-line MS
analysis of gas phase products. (b) BAS band intensities relative to the dehydrated zeolite. (c) Absolute band intensities of the 1510 and $1620 \mathrm{~cm}^{-1}$ bands recorded at 2 analysis of gas phase products. (b) BAS band intensities relative
$\mathrm{s}$ intervals during the experiments in $(A, B$ and $C)$, respectively.

This direct formation of alkenes can be clearly seen in all three crystal sizes at lower temperatures but at $623 \mathrm{~K}$, the typical temperature for MTH catalysis, the recovery of BAS due to deprotonation of SMS can be seen only in the initial methanol pulse in large crystals. The formation of alkenes (and aromatics) at this temperature is associated with the presence of the HCP species i.e. is indirect.

3.4 Continuous Flow of DME. To understand better the chemistry of the HCP species responsible for the 1510 and $1620 \mathrm{~cm}^{-1}$ bands and the effects of crystal size on the formation and reaction of these species under steady-state conditions, we turned to a continuous flow of DME (rather than methanol pulses). DME is readily converted to hydrocarbons over ZSM-5 catalysts. ${ }^{26}$ Analysis of the $\mathrm{v}(\mathrm{CH})$ region of spectra measured in the presence of DME is more difficult because of the overlapping bands of both gas phase DME and hydrogen bonded DME, and we will present a detailed investigation of these spectra elsewhere. It is useful however to examine the $1650-1450 \mathrm{~cm}^{-1}$ region together with the MS analyses in the context of the present discussion of crystal size effects on HCP formation (Figures 8-10). 

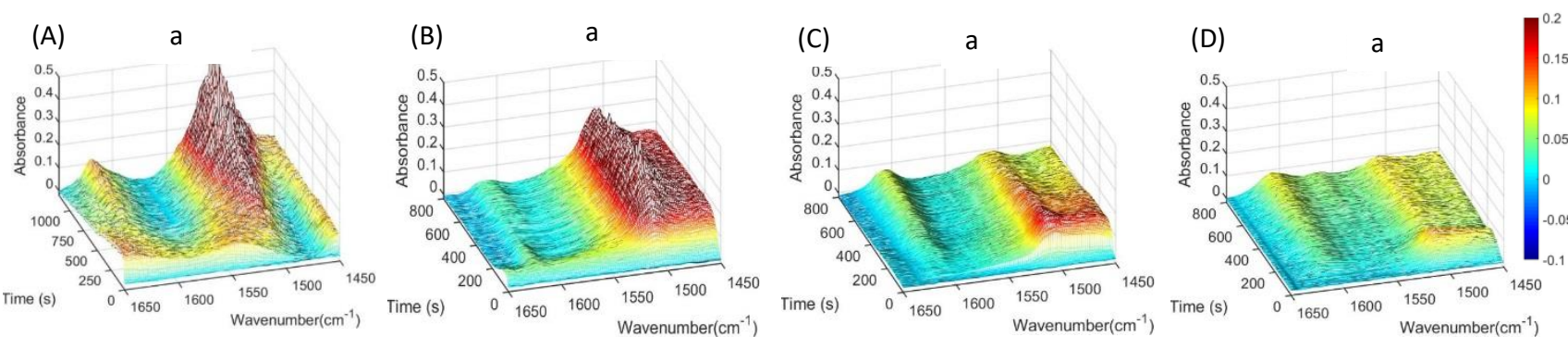

b

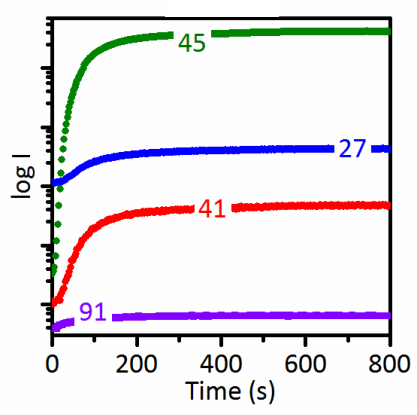

b

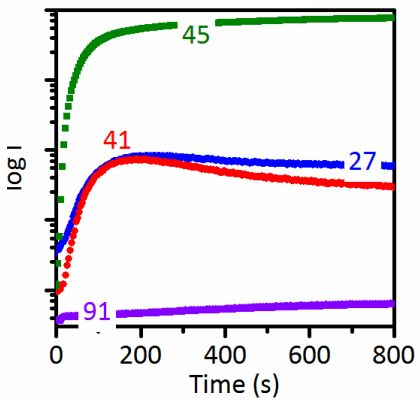

b

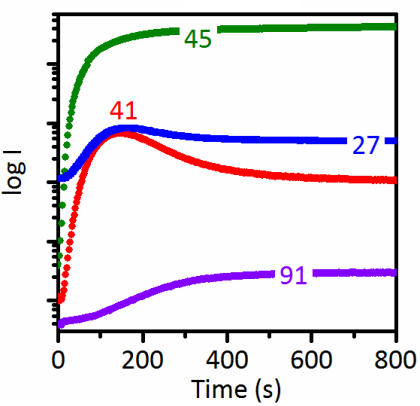

b

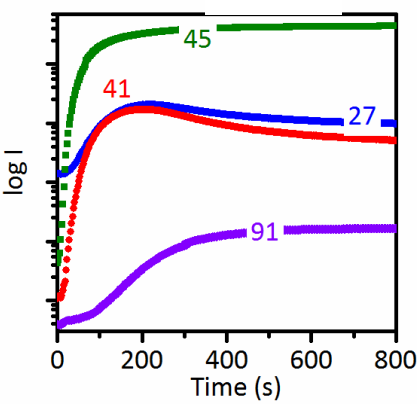

Fig 8 Continuous flow of dimethylether over a large crystal of HZSM-5 at (A) $523 \mathrm{~K}$; (B) $573 \mathrm{~K}$; (C) $623 \mathrm{~K}$ and (D) $673 \mathrm{~K}$. (a) IR spectra recorded at $2 \mathrm{~s}$ intervals. (b) OnlineMS analysis of gas phase products during the experiments in (A-D), respectively.

(A)

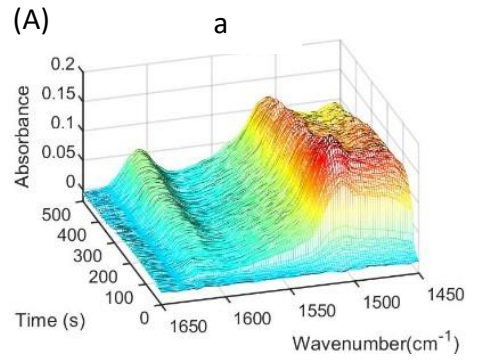

b

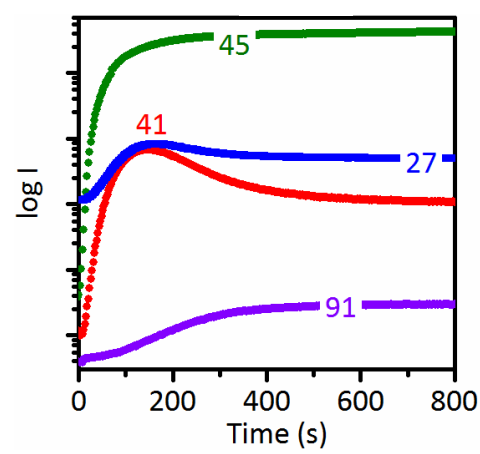

(B)

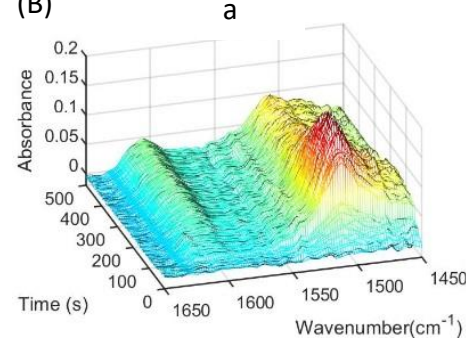

b

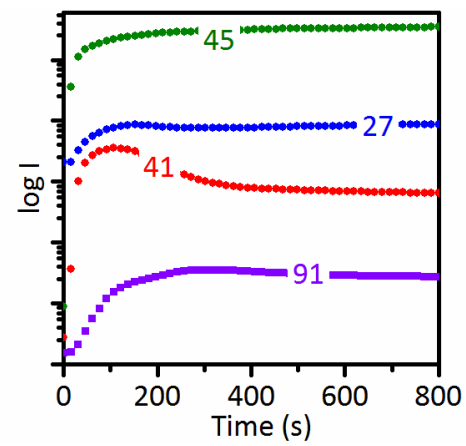

(C)
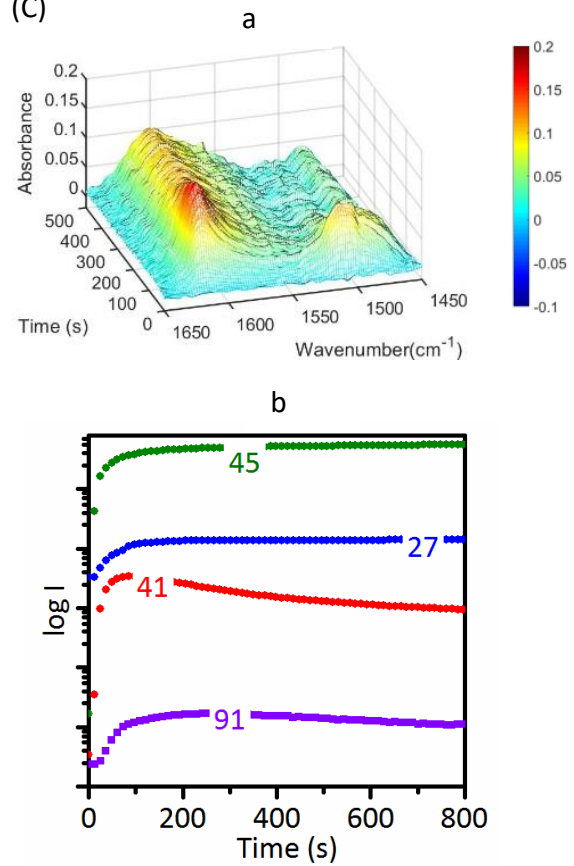

Fig. 9. Comparison of (A) large, (B) medium and (C) small HZSM-5 crystal during a continuous flow of dimethylether at $623 \mathrm{~K}$ for 8 min. (a) IR spectra recorded at $2 \mathrm{~s}$ intervals. (b) On-line MS analysis of gas phase products during the experiments in ( $A, B$ and $C$ ), respectively

At $523 \mathrm{~K}$ the 1510 and $1480 \mathrm{~cm}^{-1}$ bands of DMCP appear after a short delay and continue to grow in intensity over the duration of the experiment (Fig. 8-A). The MS analysis shows little evidence of alkene formation at this temperature; the observed $\mathrm{m} / \mathrm{z}=41$ signal results from fragmentation of DME in the mass spectrometer. At this temperature, any alkenes formed are evidently oligomerised in the zeolite and slowly react to form DMCP. Also evident at $523 \mathrm{~K}$ is the very slow growth of a $1620 \mathrm{~cm}^{-1}$ band, indicating that there is some further reaction to form aromatics at this temperature, although none escape from the zeolite. At $573 \mathrm{~K}$, the 1510 and $1460 \mathrm{~cm}^{-1}$ bands of DMCP rise quickly, plateau and remain constant thereafter (Fig. 8-B). Weak, but evident is the $1620 \mathrm{~cm}^{-1}$ band of methyl aromatics which broadens and shifts to lower frequency at $1607 \mathrm{~cm}^{-1}$ after about $400 \mathrm{~s}$ of flowing DME over the large HZSM-5 crystal, suggesting further 
evolution of the adsorbed methyl aromatics. The MS traces at $573 \mathrm{~K}$ show enhanced levels of propene and ethene, but still very little evolved methyl aromatics.

At $623 \mathrm{~K}$, the steady state concentration of DMCP in the zeolite is considerably less than at lower temperatures (Fig. 8-C). There is an increased contribution to the spectrum from the $1620 \mathrm{~cm}^{-1}$ band, and in the MS traces the initial yields of propene and ethene decline as the evolution of methylaromatics increases. The generation of methylaromatic species $(\mathrm{m} / \mathrm{z}=91)$ is more prominent at $673 \mathrm{~K}$, but the IR spectra are more complex. Within $200 \mathrm{~s}$, multiple bands are observed at $1607,1566,1510,1490,1460 \mathrm{~cm}^{-1}$, suggesting formation of a more varied HCP at this temperature (Fig. 8-D).

A striking difference in the DMCP concentration between large and small crystals was observed during the isothermal continuous flow of DME at $623 \mathrm{~K}$ (Fig. 9). The density and strength of acid sites has not changed, and the product distributions at longer reaction times are quite similar, although the steady state evolution of methylaromatics is achieved more quickly in the smaller crystals. The decomposition of DMCP species to generate methylaromatics evidently occurs more quickly in the smallest crystals.

Similar effects were seen at $673 \mathrm{~K}$ (Fig. 10). In both large and small crystals a complex set of bands is seen in the 1650$1450 \mathrm{~cm}^{-1}$ region but there is a larger contribution from bands in the $1550-1650 \mathrm{~cm}^{-1}$ region in the small crystals, consistent with the more rapid evolution of methylaromatic products in the MS traces. At this temperature the crystals contain many of the HCP species detected by NMR and UV-VIS spectroscopy. ${ }^{12,13}$
(A)

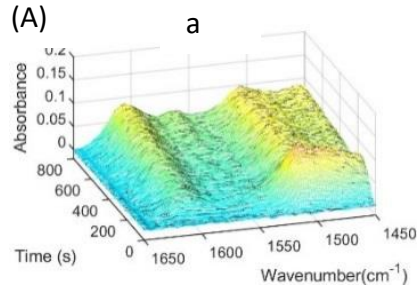

b

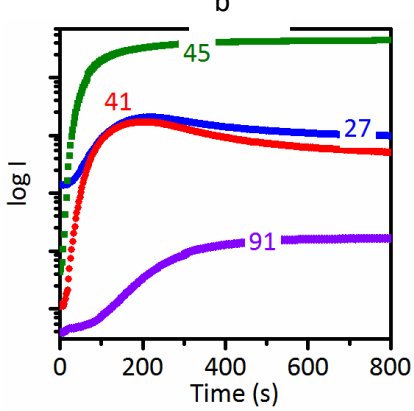

(B)

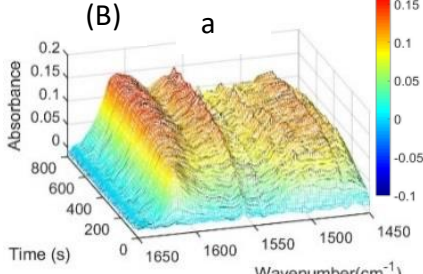

b

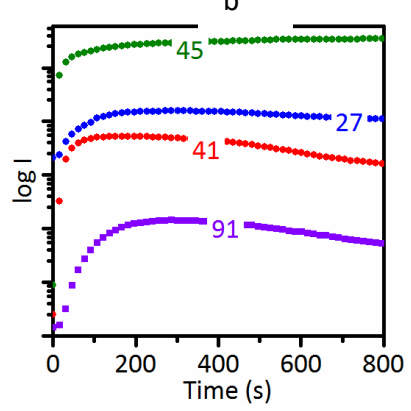

Fig 10 Comparison of (A) large and (B) small HZSM-5 crystal during continuous flow of dimethylether at $673 \mathrm{~K}$ over $13 \mathrm{~min}$. (a) IR spectra recorded at $2 \mathrm{~s}$ intervals. (b) On-line MS analysis of gas phase products during the experiments in (A) and (B), respectively.

The continuous flow DME experiments show that the DMCP species which we identify as the first cyclic component of the $\mathrm{HCP}$ is formed in high concentrations in the zeolite already at
$523 \mathrm{~K}$, but with little formation of gas phase products at this temperature.

The infrared signature of adsorbed methyl aromatics $\left(1620 \mathrm{~cm}^{-1}\right)$ begins to appear after the DMCP $\left(1510 \mathrm{~cm}^{-1}\right)$. At higher temperatures cracking of the DMCP to form alkene products is accompanied by the further reaction to generate methyl aromatics, and both of these processes depend on crystal size. In particular, the conversion of DMCP species to methyl aromatics is favoured in smaller crystals, probably because of faster diffusion of DME reactant into the pores.

\section{Conclusions}

Operando infrared microspectroscopy (OIMS) performed with synchrotron radiation is a powerful tool to study the formation mechanism of the initial hydrocarbon pool species within individual crystals of ZSM-5. In this study we have confirmed the reaction sequence proposed elsewhere, ${ }^{8}$ in which the direct formation of alkenes in the very initial stages of methanol conversion is due to deprotonation of SMS. Once alkenes are formed, these alkenes oligomerize at BAS; the oligomer can either crack or can cyclize to form DMCP as the first cyclic component of the hydrocarbon pool which can also release alkenes or react further to form the methylaromatic components of the hydrocarbon pool. We show that the OIMS enabled us to follow reactions on crystals down to 30 microns in size, with a time resolution of $2 \mathrm{~s}$ routinely, and down to $0.25 \mathrm{~s}^{8}$

The important conclusion regarding the significance of crystal size is that the induction time for deprotonation of SMS, regeneration of BAS and formation of alkenes decreases as the crystal size is reduced. We attribute this to the faster desorption of hydrogen bonded DME out of the smaller crystals i.e. the presence of excess DME in the crystals appears to block the SMS deprotonation chemistry.

These studies have shown that it will be difficult to detect direct formation of alkenes in much smaller micron sized crystals, since the HCP species are seen to form very quickly in smaller crystals, and the cracking of these is responsible for the observed steady-state alkene yields from both methanol and dimethylether. Based on this, we suggest that the induction periods for alkene formation seen in many conventional catalytic studies cannot be due to intra-crystalline chemistry but must be attributed to diffusion of reactants into the catalyst bed or of products out of the catalyst bed.

Finally we note the potential of the method to be applied to other zeolite catalysts and catalytic reactions, given crystal sizes of at least $\mathbf{2 0}$ microns for satisfactory signal-to-noise ratios, and the possibility of extending the measurements to time dependent spectra from several adjacent crystals using automatic mapping functionality common to the IR microscope acquisition software. The signal to noise advantage gained from synchrotron radiation will also allow diffusion measurements on zeolite crystals previously performed with laboratory infrared microscopes ${ }^{27,28}$ to be extended to much shorter time scales. 


\section{Acknowledgements}

IBM and PAW would like to thank the EPSRC and CRITICAT Centre for Doctoral Training for Financial Support [PhD studentship to IBM, and supplementary equipment grant EP/L016419/1]. The UK Catalysis Hub is thanked for resources and support provided via membership of the UK Catalysis Hub Consortium and funded by EPSRC (grants EP/I038748/1, EP/I019693/1, EP/K014706/1, EP/K014668/1, EP/K014854/1, $\mathrm{EP} / \mathrm{K} 014714 / 1$ and EP/M013219/1). We thank the Diamond Light Source for provision of beam time and support facilities at the MIRIAM beamline B22 (Experiments SM13725-1, SM162571, SM18680-1, SM20906-1).

There are no conflicts to declare.

\section{Notes and references}

1 S. Bordiga, C. Lamberti, F. Bonino, A. Travert and F. ThibaultStarzy, Probing Zeolites by Infrared Spectroscopy, Chem.Soc.Rev. 2915, 44, 7262-7341.

2 S. C. Popescu, S. Thomson and R. F. Howe, Microspectroscopic Studies of Template Interactions in AIPO-5 and SAPO-5 Crystals, Phys.Chem.Chem.Phys. 2001, 3, 111-118.

3 A. Greenaway, B. Gonzalez-Santiago, P. M. Donaldson, M. D. Frogley, G. Cinque, J. Sotelo, S. Moggach, E. Shiko, S. Brandani, R. F. Howe and P. A. Wright, In situ Synchrotron IR Microspectroscopy of $\mathrm{CO}_{2}$ Adsorption on Single Crystals of the Functionalized $\mathrm{MOF} \mathrm{Sc}_{2}\left(\mathrm{BDC}-\mathrm{NH}_{2}\right)_{3}$, Angewandte Chemie International Edition, 2014, 53, 13483-13487.

4 E. Stavitski, M. H. F. Kox, I. Swart, F. M. F. de Groot and B. M. Weckhuysen, In Situ Synchrotron-Based IR Microspectroscopy To Study Catalytic Reactions in Zeolite Crystals, Angewandte Chemie International Edition, 2008, 47, 3543-3547.

5 E. Stavitski, E. A. Pidko, M. H. F. Kox, E. J. M. Hensen, R. A. van Santen and B. M. Weckhuysen, Detection of Carbocationic Species in Zeolites: Large Crystals Pave the Way, Chemistry - $A$ European Journal, 2010, 16, 9340-9348.

6 F. Meirer and B. M. Weckhuysen, Spatial and temporal exploration of heterogeneous catalysts with synchrotron radiation, Nature Reviews Materials, 2018, 3, 324-340.

7 E. Stavitski and B. M. Weckhuysen, Infrared and Raman imaging of heterogeneous catalysts, Chem. Soc. Rev., 2010, 39, 46154625.

8 I. B. Minova, S. K. Matam, A. Greenaway, C. R. A. Catlow, M. D. Frogley, G. Cinque, P. A. Wright and R. F. Howe, Elementary Steps in the Formation of Hydrocarbons from Surface Methoxy Groups in HZSM- 5 Seen by Synchrotron Infrared Microspectroscopy, ACS Catal., 2019, 9, 6564-6570.

9 C. D. Chang, Hydrocarbons from Methanol, Catal. Rev. Sci. Eng. 1983, 25, 1-118.

10 S. Xu, Y. Zhi, J. Han, W. Zhang, X. Wu, T. Sun, Y. Wei and Z. Liu, Advances in Catalysis for Methanol to Olefin Conversion, Advan.Catal. 2017, 61, 37-119.

11 J. F. Haw, W. Song, D. M. Marcus and J. B. Nicholas, The Mechanism of Methanol to Hydrocarbon Catalysis, Acc. Chem. Res., 2003, 36, 317-326.

12 U. Olsbye, S. Svelle, K. P. Lillerud, Z. H. Wei, Y. Y. Chen, J. F. Li, J. G. Wang and W. B. Fan, The Formation and Degradation of Active Species During Methanol Conversion over Protonated Zeotype Catalysts, Chemical Society Reviews, 2015, 44, 7155-7176.
13 I. Yarulina, A. D. Chowdhury, F. Meirer, B. M. Weckhuysen and J. Gascon, Recent trends and fundamental insights in the methanolto-hydrocarbons process, Nature Catalysis, 2018, 1, 398-411.

14 A. J. O'Malley, S. F. Parker, A. Chutia, M. R. Farrow, I. P. Silverwood, V. García-Sakai and C. R. A. Catlow, Room Temperature Methoxylation in Zeolites: Insight Into a Key Step of the Methanol-to-Hydrocarbons Process, Chem. Commun., 2016, 52, 2897-2900.

15 S. K. Matam, R. F. Howe, A. Thetford and C. R. A. Catlow, Room temperature methoxylation in zeolite $\mathrm{H}-\mathrm{ZSM}-5$ : an operando DRIFTS/mass spectrometric study, Chem. Commun., 2018, 54, 12875-12878.

16 J. L. Guth, H. Kessler and R. Wey, in Studies in Surface Science and Catalysis, eds. Y. Murakami, A. lijima and J. W. Ward, Elsevier, 1986, vol. 28, pp. 121-128.

17 P. Losch, A. B. Pinar, M. G. Willinger, K. Soukup, S. Chavan, B. Vincent, P. Pale and B. Louis, H-ZSM-5 Zeolite Model Crystals: Structure-Diffusion-Activity Relationship in Methanol-to-Olefins Catalysis, Journal of Catalysis, 2017, 345, 11-23.

18 P. Sazama, B. Wichterlova, J. Dedecek, Z. Tvaruzkova, Z. Musilova, L. Palumbo, S. Sklenak and O. Gonsiorova, FTIR and ${ }^{27}$ AI MAS NMR Analysis of the Effect of Framework Al- and Si-defects in Microand Micro-Mesoporous H-ZSM-5 on Conversion of Methanol to Hydrocarbons, Microporous and Mesoporous Materials, 2011, 143, 87-96.

19 P. Sarv, C. Fernandez, J.-P. Amoureux and K. Keskinen, Distribution of Tetrahedral Aluminium Sites in ZSM-5 Type Zeolites: An ${ }^{27} \mathrm{Al}$ (Multiquantum) Magic Angle Spinning NMR Study, J. Phys. Chem., 1996, 100, 19223-19226.

20 C. A. Fyfe, Y. Feng, H. Grondey, G. T. Kokotailo and H. Gies, Oneand two-dimensional high-resolution solid-state NMR studies of zeolite lattice structures, Chem. Rev., 1991, 91, 1525-1543.

21 L. Karwacki, M. H. F. Kox, D. A. Matthijs de Winter, M. R. Drury, J. D. Meeldijk, E. Stavitski, W. Schmidt, M. Mertens, P. Cubillas, N. John, A. Chan, N. Kahn, S. R. Bare, M. Anderson, J. Kornatowski and B. M. Weckhuysen, Morphology-Dependent Zeolite Intergrowth Structures Leading to Distinct Internal and OuterSurface Molecular Diffusion Barriers, Nature Materials, 2009, 8, 959-965.

22 W. Wang, A. Buchholz, M. Seiler and M. Hunger, Evidence for an Initiation of the Methanol-to-Olefin Process by Reactive Surface Methoxy Groups on Acidic Zeolite Catalysts, Journal of the American Chemical Society, 2003, 125, 15260-15267.

23 J. N. Kondo, H. Yamazaki, T. Yokoi and T. Tatsumi, Mechanisms of reactions of methoxy species with benzene and cyclohexane over H-ZSM-5 zeolites, Catal. Sci. Technol., 2015, 5, 3598-3602.

24 J. F. Haw, J. B. Nicholas, W. Song, F. Deng, Z. Wang, T. Xu and C. S. Heneghan, Roles for Cyclopentenyl Cations in the Synthesis of Hydrocarbons from Methanol on Zeolite Catalyst H-ZSM-5, J. Am. Chem. Soc., 2000, 122, 4763-4775.

25 J. D. Mosley, J. W. Young, J. Agarwal, H. F. Schaefer, P. v R. Schleyer and M. A. Duncan, Structural isomerization of the gasphase 2-norbornyl cation revealed with infrared spectroscopy and computational chemistry, Angew. Chem. Int. Ed. Engl., 2014, 53, 5888-5891.

26 P. Perez-Unarto, A. Ateka, A. C. Gayubo, T. Coruro-Lanzar, A. T. Aguayo and J. Bilbao, Decativation Kinetics for Coversion of Dimethylether to Olefins over a HZSM-5 Catalyst, Chem.Eng.J. 2017, 311, 367-377. 
27 J.Karger, T.Binder, C.Chmelik, F.Hibbe, H.Krautscheid, R.Krishna and J.Weitkamp, Microimaging of Transient Guest Profiles to Monitor Mass Transfer in Nanoporous Materials, Nature Materials, 2014, 13, 333-343.

28 T.Titze, C.Chmelik, J.Kullmann, L.Prager, E.Miersemann, R.Glaser, D.Enke, J.Weitkamp and J.Karger, Microimaging of Transient Concentration Profiles of Reactant and Product Molecules during Catalytic Conversion in Nanoporous Materials, Angewandte Chem.Int.Ed. 2015, 54, 5060-5064. 